\title{
Eradication of diffuse gastric Peutz-Jeghers polyps by unsedated transnasal snare polypectomy and argon plasma coagulation
}

Peutz-Jeghers syndrome (PJS) is a rare, autosomal dominant disease characterized by hamartomatous gastrointestinal polyps, mucocutaneous pigmentation, and family history of PJS [1]. Rarely, solitary Peutz-Jeghers polyps occur, without other features of PJS, and are associated with an increased risk of gastrointestinal and gynecological cancers. Transnasal ultrathin esophagogastroduodenoscopy (EGD) has an important role in the diagnosis and treatment of Peutz-Jeghers polyps because it is highly tolerable and is also safer than peroral EGD $[2,3]$.

A 74-year-old woman was referred to our hospital for ultrathin EGD because she had hypoxemia during peroral EGD. Her conjunctivae were pale, without any mucocutaneous pigmentation, and her hemoglobin was $5.3 \mathrm{~g} / \mathrm{dL}$ (hematocrit 18.6\%). An ultrathin EGD (EG-530N endoscope; Fujinon, Tokyo, Japan) revealed multiple polyps throughout the stomach ( $\bullet$ Fig. 1). Initially we carried out transnasal argon plasma coagulation (APC; $1.5 \mathrm{~mm}$ diameter Model P5 APC probe, Fujinon) of the hematin-coated polyps ( $\bullet$ Fig. 2 a) and the patient was transfused with $500 \mathrm{~mL}$ packed red blood cells. A second-look ultrathin EGD revealed more blood-oozing polyps. We then carried out transnasal snare polypectomy $(1.8 \mathrm{~mm}$ diameter FTE-Polypectomy snare, Fujinon) of the pedunculated and large, sessile polyps, followed by APC of the cut margin, ablating the polyp remnants to prevent recurrence ( $\mathbf{F i g . 2}$ ). Histologic examination of the polypectomized polyp, but not the biopsy sample taken at our hospital, confirmed the diagnosis of Peutz-Jeghers polyps, and one of the polypectomized polyps demonstrated dysplasia ( $\bullet$ Fig. 3 c,d). In three outpatient sessions at weekly intervals, we eradicated 32 polyps using transnasal snare polypectomy with APC of the cut margins and remnants of the polyps. The patient tolerated all the procedures, without any complications. Repeat ultrathin EGD with biopsy carried out 1 week and 8 months later confirmed eradication of the Peutz-Jeghers polyps with healed mucosa ( $\bullet$ Fig. 1 c-f).
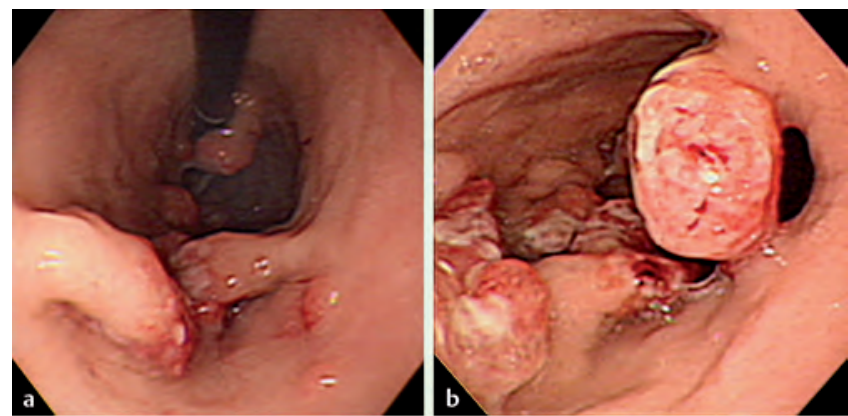

Fig. 1 Endoscopic views of gastric PeutzJeghers polyposis: a, b before treatment; c, $\mathbf{d} 1$ week after the last session of transnasal polypectomy and argon plasma coagulation (APC); and

e, $f 8$ months after the last session of treat-
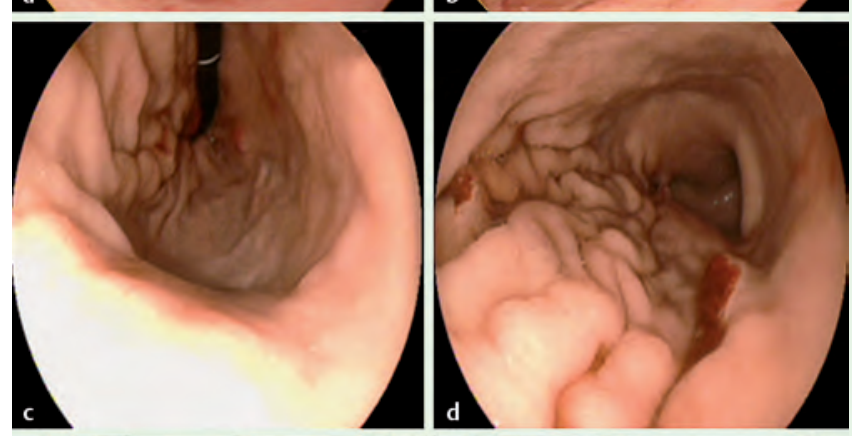

ment.
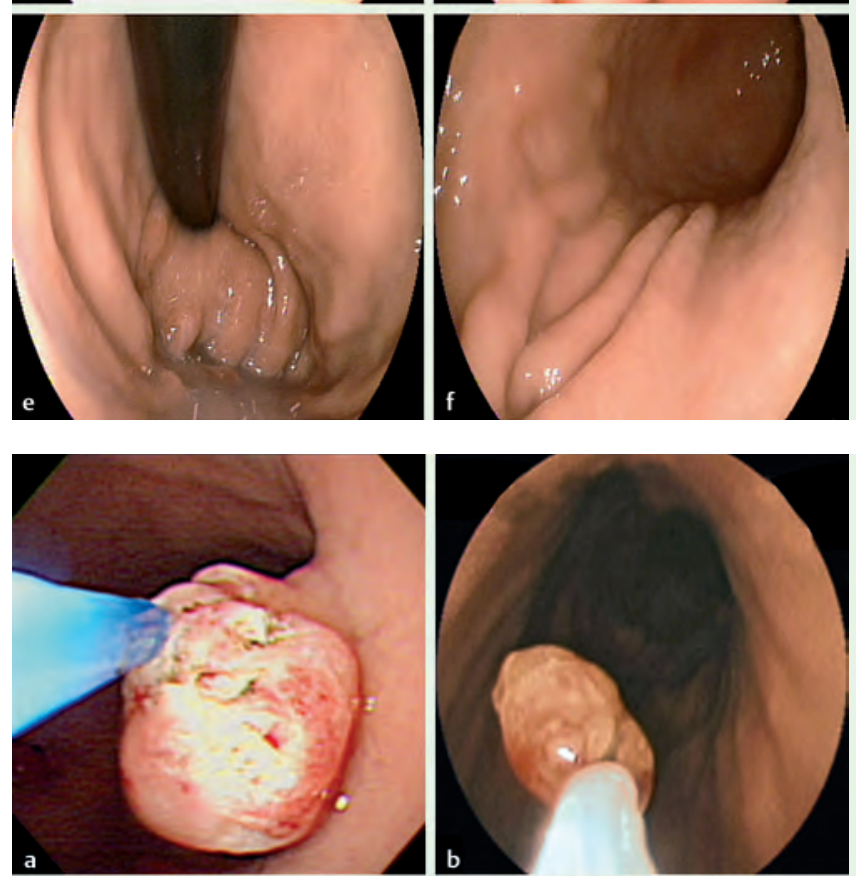

Fig. 2 a Transnasal argon plasma coagulation (APC) of a bleeding polyp. b A polyp caught by a polypectomy snare, $\mathbf{c}$ being removed through the right nasal cavity, $\mathbf{d}$ and finally being taken out of the right anterior naris, without any complica-
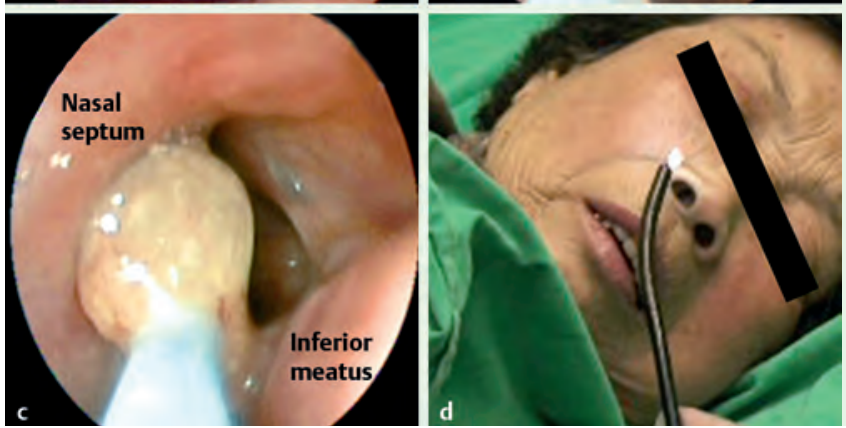

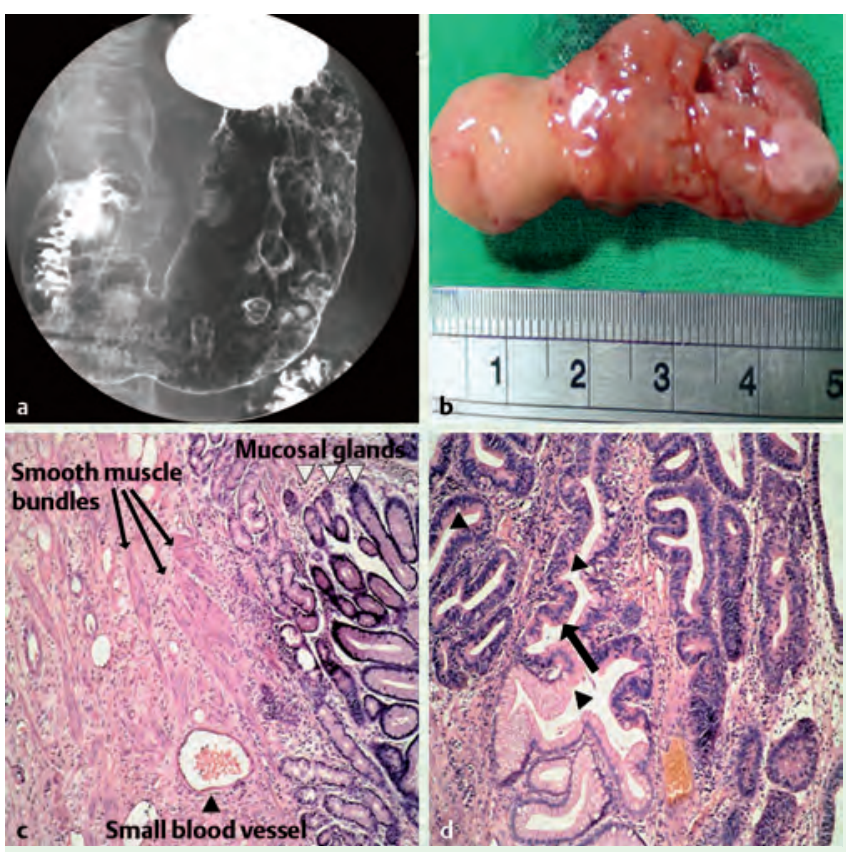

Fig. 3 a Small-bowel series showing multiple polyps in the stomach but not in the small intestine. $\mathbf{b}$ The largest polyp removed from the nasal cavity by transnasal polypectomy measured $4.8 \times 2.5 \times 2.0 \mathrm{~cm}$. c Microscopic view (hematoxylin and eosin stain, $\times 400$ ) shows pathognomic findings of Peutz-Jeghers polyps: clusters of foveolar glands, inflammatory cell infiltration, and proliferation of smooth muscle bundles and small blood vessels.

d A Peutz-Jeghers polyp showing dysplastic transformation with intestinal-type glands (arrow) characterized by higher nuclear:cytoplasmic $(\mathrm{N}: \mathrm{C})$ ratio and scant mucin-rich goblet cells (small arrowheads) compared with the gastric-type glands (large arrowhead) with low N/C ratio and abundant mucin-rich cells.

\section{References}

1 McGarrity TJ, Kulin HE, Zaino RJ. Peutz-Jeghers syndrome. 2000; 95: 596-604

2 Faulx AL, Catanzaro A, Zyzanski S et al. Patient tolerance and acceptance of unsedated ultrathin esophagoscopy. Gastrointest Endosc 2002; 55: 620-623

3 Kim CY, O'Rourke RW, Chang EY et al. Unsedated small-caliber upper endoscopy: an emerging diagnostic and therapeutic technology. Surg Innov 2006; 13: 31 - 39

4 Gopal DV, Zaman A, Katon RM. A role for transnasal esophagogastroduodenoscopy in patients intolerant to the oral route: report of two cases. Gastrointest Endosc 1999; 49: 379- 381

5 Scott-Coombes DM, Thompson JN. Hypoxia during upper gastro-intestinal endoscopy is caused by sedation. Endoscopy 1993; 25: $308-309$

Bibliography

DOI $10.1055 / \mathrm{s}-0029-1214805$

Endoscopy 2009; 41: E207-E208

(c) Georg Thieme Verlag KG Stuttgart · New York . ISSN 0013-726X

\section{Corresponding author}

\section{Hu, MD, PhD}

Division of Gastroenterology

Department of Internal Medicine

Buddhist Tzu Chi Hospital and Tzu Chi University

No 707 Section 3

Chung Yang Road

Hualien (970)

Taiwan

Fax: +886-3-8577161

chitan.hu@msa.hinet.net 